\title{
La auto-regulación en las Cooperativas No Agropecuarias cubanas. Propuestas para su optimización mediante la asesoría jurídica
}

(The self-regulation in the Cuban Non-Agricultural Cooperatives.

Proposals for the optimization through the legal advice)

Orisel Hernández Aguilar ${ }^{1}$, Orestes Rodríguez Musa²

Universidad de Pinar del Río, Cuba

Martha Beatriz Martínez de Osaba Fontanella ${ }^{3}$

Empresa Provincial de Servicios Legales de Pinar del Río, Cuba

Sumario: I. Introducción. II. La auto-regulación como expresión del principio de autonomía e independencia: alcance y contenido. III. Marco legal para la auto-regulación en las Cooperativas no Agropecuarias cubanas. IV. Perfeccionamiento de la auto-regulación en las Cooperativas no Agropecuarias cubanas mediante la asesoría jurídica. $\checkmark$. Conclusiones.

Summary: I. Introduction. II. Self-regulation as an expression of the principle of autonomy and independence: scope and content. III. Legal framework for the self-regulation in Cuban non-agricultural Cooperatives. IV. Improvement of the self-regulation in Cuban NonAgricultural Cooperatives through legal advice. V. Conclusions.

Resumen: El objetivo de este trabajo es fundamentar algunas propuestas para contribuir, desde la asesoría jurídica, al perfeccionamiento de la auto-regulación en las Cooperativas No Agropecuarias cubanas. Para ello, se sistematiza el alcance y los contenidos de la auto-regulación como expresión del principio de autonomía e independencia. A continuación, se valora el marco legal vigente para la auto-regulación en las Cooperativas no Agropecuarias cubanas. Por último, se argumentan un conjunto de recomendaciones que pueden con-

\footnotetext{
E-mail: orisel@upr.edu.cu

E-mail:musa@upr.edu.cu

3 E-mail: marthab@epselpr.co.cu
} 
tribuir a optimizar dicha auto-regulación mediante la asesoría jurídica que reciben estas cooperativas cubanas.

Palabras claves: cooperativa; autonomía; auto-regulación; asesoría jurídica.

Abstract: The objective of this work is to base some proposals to contribute, from legal advice, to the improvement of the self-regulation in Cuban Non-Agricultural Cooperatives. For this, the scope and contents of the self-regulation are systematized as an expression of the principle of autonomy and independence. Next, the current legal framework for the self-regulation in $\mathrm{Cu}$ ban Non-Agricultural Cooperatives is valued. Finally, a set of recommendations that can contribute to optimize this self-regulation through the legal advice received by these Cuban cooperatives are argued.

Keywords: cooperative; autonomy; self-regulation; legal advice. 


\section{Introducción}

El principio de autonomía e independencia quedó definido en la Declaración sobre la Identidad Cooperativa, aprobada en el Congreso de Manchester en 1995, en los términos que siguen: "Las cooperativas son organizaciones autónomas de auto ayuda, administradas por sus asociados. Si intervienen en acuerdos con otras organizaciones, incluidos los gobiernos, o captan capital de fuentes externas, lo hacen en términos que aseguren el control por parte de los asociados y mantengan su autonomía cooperativa» (Alianza Cooperativa Internacional, 1995).

Por su importancia, es cada vez más común que la legislación especial de la materia haga suya la definición de los principios cooperativos universalmente reconocidos - bien sea con carácter obligatorio o indicativo (GARCíA Müller 2006, 86)— sobre todo en América Latina, región que se ha caracterizado por un fuerte "principismo» (CRACOGNA 2001). Esta tendencia implica obviamente a la «autonomía e independencia», denominador común en la parte general de muchas legislaciones, incluso, con concepciones diversas sobre la naturaleza jurídica de la institución.

El reconocimiento a estas reglas ha trascendido el ámbito del cooperativismo nacional, dando lugar a que la Organización Internacional del Trabajo (OIT), en su Recomendación sobre la promoción de las cooperativas de 2002, abogue por el establecimiento de políticas y marcos jurídicos favorables que resulten compatibles con la institución, exhortando en su párrafo 6 , inciso c) por el particular respeto hacia su autonomía.

A pesar de lo anterior, la complejidad de esta cuestión no permite simplificaciones, pues tratarla implica adentrarse en un espacio de escasa sistematización teórica, máxime cuando el régimen jurídico de la cooperativa depende de la traducción que realice el legislador de su naturaleza, cuestión nada pacífica en la doctrina jurídica y diversa en el Derecho comparado.

En Cuba, el tema ha sido de interés creciente y su presencia transversaliza las investigaciones de los últimos cinco años, haciéndose particularmente notable en aquellas que ofrecen enfoques más complejos y completos del fenómeno (Cfr.: Fajardo García y Moreno Cruz 2018; Rodríguez Musa y Hernández Aguilar 2018 a.). Ello obedece, en gran medida, a la expansión de la cooperativa a sectores de la economía distintos del agropecuario como parte del proceso de actualización de su modelo socioeconómico, que conllevó a la creación de las Cooperativas no Agropecuarias (CNA). 
En líneas generales Rodríguez Musa (2013), sistematizando las características del principio de autonomía en el sector cooperativo de la Isla, sostiene que al regularse las relaciones jurídicas entre el Estado y las cooperativas se ha asumido un modelo absorbente (CRACOGNA 2001 ) o de dependencia (Rosemburg 1985, 104) que ha limitado en diversos aspectos y de forma sustancial la autonomía que debe caracterizar a la figura. Sin embargo, el citado autor admite que las noveles entidades cuentan con oportunidades para desarrollar la autogestión y el autocontrol, lo cual — tal vez- podría atribuirse el carácter experimental de las mismas (Vid. Segundo POR CUANTO y artículo 1 del DL305/12).

Haciendo un balance del desarrollo de las CNA hasta la fecha se constata que este proceso ha estado marcado por varias limitaciones (Rodríguez Musa y Hernández Aguilar 2018 b.), pese a que en el país existen un conjunto de condiciones objetivas y subjetivas que deben ser aprovechadas en pos de transformar esta realidad.

Ante tal escenario, la asesoría jurídica, como modo de actuación del profesional del Derecho, se presenta como un medio para contribuir — de múltiples formas - a la óptima utilización de la autonomía para fortalecer la identidad de las cooperativas. Al respecto se ha ganado consenso en espacios científicos, llegándose a admitir que «la capacidad de autorregulación de las cooperativas, unido a una labor de asesoría jurídica de calidad, tiene potencialidades para superar la mayor parte de las limitaciones que hoy presentan las experiencias prácticas relativas a estas formas asociativas en Cuba» (COODER II, 2018).

En esta última dirección trabaja el Departamento de Derecho de la Universidad de Pinar del Río (DD-UPR), de conjunto con la Empresa Provincial de Servicios Legales (EPSEL), como parte del Proyecto de Investigación, Desarrollo e Innovación (I+D+i) «Metodología para el perfeccionamiento del proceso de asesoría jurídica de las CNA de la provincia de Pinar del Río, desde su gestación hasta su disolución». Este empeño tiene como propósito central contribuir, desde el proceso de asesoría jurídica, al fortalecimiento de la identidad de estas figuras en la provincia de Pinar del Río.

En este Proyecto se han definido múltiples indicadores hacia los cuales la nueva Metodología habrá de dirigir sus recomendaciones, entre ellas se encuentra la «autonomía», siendo una de las que mayor alcance, dado su carácter trasversal.

Habida cuenta de lo anterior, el presente trabajo tiene por objetivo fundamentar algunas propuestas para contribuir, desde la asesoría jurídica, con el fortalecimiento de la auto-regulación de las CNA. La selección de esta arista particular de la autonomía obedece, en lo funda- 
mental, a dos razones: la primera es de tipo metodológico, toda vez que la complejidad del principio en cuestión supondría atender una multiplicidad de implicaciones que sobrepasan los límites posibles en este tipo de trabajo; y la segunda, de índole práctica, puesto que se trata de enfocar la atención a un aspecto de la materialización de este principio cooperativo que está al alcance de los asesores y asociados, permitiendo así su concreción con mayor inmediatez.

Para cumplimentar el propósito de este artículo, a continuación se sistematizan el alcance y contenidos de la auto-regulación cooperativa, en tanto es expresión del principio de autonomía e independencia. Seguidamente, se valora el marco legal cubano para la auto-regulación de las CNA. Por último, se argumentan un grupo de recomendaciones que pueden contribuir al perfeccionamiento de la auto-regulación en las Cooperativas no Agropecuarias, mediante la asesoría jurídica.

\section{La auto-regulación como expresión del principio de autonomía e independencia: alcance y contenido}

Como se apuntó antes, la autonomía ha de ser un elemento que atraviese de forma transversal a todas aquellas disposiciones jurídicas relativas a la cooperativa. Su espíritu debe superar las frías definiciones legales e informar, de inicio a fin, la instrumentación jurídica de la figura mediante elementos concretos. Sin embargo, el reconocimiento expreso del principio, además de resultar valioso para tipificar el fenómeno cooperativo, dota a la autonomía de la legalidad que requiere su efectiva protección, operando como prerrequisito indispensable para que se puedan desplegar sus efectos consustanciales.

Partiendo entonces de que «la autonomía de una entidad no es un presupuesto declarativo, formal, sino que posee contenido material, manifestado entre otros en facultades de decisión, autogestión y su aparejada responsabilidad» (FerNÁNDEZ PeISO 2006, 41), no resulta difícil comprender que esta tenga un reflejo natural en la capacidad de autonormar, de autorregular, el desarrollo de la aludida entidad.

Esta suerte de «potestad legislativa secundaria, subordinada y derivada» (PACHECO 1993, 368), se encuentra en las corporaciones - cualquier que sea su tipo-y tiene como finalidad asegurar que las mismas puedan dictar sus propias normas internas. La validez de estos actos corporativos, como fuentes formales de normas jurídicas, emana del reconocimiento otorgado por el Estado.

La particularidad que distingue la auto-regulación cooperativa de la auto-regulación corporativa radica en que su fundamento descansa 
no en la autorización para auto-reglamentarse emitida por parte de los poderes públicos, sino que se trata de un elemento consustancial al principio cooperativo de autonomía e independencia. Por tal motivo, el alcance y contenido de esta facultad es mayor, como se verá seguidamente.

A ello habría que sumar otro aspecto distintivo, que no se evidencia de igual manera en los actos corporativos generadores de normas, y es el hecho de que las cooperativas producen sus regulaciones en un régimen democrático-inclusivo, donde los sujetos regulados son, a la vez, sujetos reguladores de su actividad. Como afirma CALlowAY, "La autorregulación no es impuesta (...), ya que es el producto de las decisiones colectivas en función de generar un marco normativo que permita la convivencia laboral, la producción y la gestión» $(2016,17)$.

Debe hacerse notar, además que cuando se habla de auto-regulación, aunque se comprende a la autonomía estatutaria, se está rebasando también esos marcos. La auto-regulación implica toda la gama de normas generales o particulares que resulten de la ordenación colectiva, autónomamente impuesta, por y para la cooperativa, teniendo como finalidad disciplinar los distintos actos que se realicen en el ámbito de su desenvolvimiento.

El alcance de la auto-regulación está dado por las reglas generales que siga el ordenamiento jurídico en cuestión, al organizar el sistema de fuentes y los principios que explican las relaciones entre ellas.

Para comprender esta idea conviene repasar el pensamiento del profesor Cossio, quien apunta: "Las normas jurídicas se dan en una estructura piramidal porque, en el Derecho, el tránsito de una norma jurídica a otra es un proceso autorregulado: una norma jurídica vale porque es la ejecución de una norma más alta; ésta, a su vez vale porque es la ejecución de otra norma aún más general; y así, desde las normas individuales (negocios jurídicos, sentencias y decisiones administrativas), que están en la base, pasando por decretos leyes y disposiciones constitucionales, se llega, con la norma fundamental de carácter hipotético, al vértice de la pirámide» (citado en PACHECO 1993, 302).

De esta forma, se comprende que la auto-regulación cooperativa, como cualquier otro fenómeno normativo, tiene sus límites en el respeto a la legalidad, de la cual trae, además, el fundamento para su validez. Así pues, operando con la legalidad como principio de juricidad, la actuación de los entes cooperativos debe encausarse con respeto por las disposiciones legales, lo que no implica que toda actuación posible deba estar expresamente regulada, sino ser consecuente con los principios del ordenamiento jurídico, velando por su unidad y coherencia. 
En la actualidad se aboga por que, dentro de la legalidad, las relaciones entre los espacios con y sin regulación expresa se rijan de conformidad con el principio de subsidiariedad. De tal modo que «en las relaciones entre entidades institucionales y sociales de diversa dimensión la preferencia debe darse a las menores y que las intervenciones de las mayores, se justifiquen en tanto en cuanto se dirijan a suplir los eventuales inconvenientes de las primeras» (FrosinI 2002, 12).

En total sintonía con ello HeNRY (2000) sostiene que «el logro de la autonomía de las cooperativas está supeditado a la aplicación del principio de la subsidiaridad. (...) Su aplicación en el ámbito que nos interesa aquí debería permitir a cada cooperativa ser dueña de las decisiones que le interesan, a menos que éstas sean de la competencia del interés público o que obstaculicen la libertad de terceros».

Siendo así, solo deberían ser regulados a través de las normas públicas los asuntos que exceden de la competencia de una cooperativa individual (HENRŸ 2013), dejando todas las restantes cuestiones, que no estuvieran expresamente reservadas a los poderes centrales en virtud de las responsabilidades a ellos asignadas, en manos de las cooperativas.

En líneas generales, ha de entenderse que el principio de legalidad opera como legitimador y frontera de la auto-regulación, en tanto la presencia del principio de subsidiariedad funciona como una reserva abstracta, inclusiva de los contenidos sobre los que puede recaer.

Esta última cuestión, de las materias o asuntos sobre los cuales pueden darse reglas las cooperativas, amerita un análisis detenido puesto que la naturaleza y/o profundidad con que haya de hacerse la regulación está intrínsecamente ligada al tipo de instrumento jurídico a utilizar. Este particular, presenta variantes en cada ordenamiento, según la naturaleza de los diferentes asuntos que pueden ser objeto de tratamiento por parte de las cooperativas. No obstante, en este sentido existen unos marcos generales que ofrecen un relativo consenso.

En primer lugar, se encuentran los Estatutos sociales que «son la principal norma jurídica interna» (SENENT VIDAL 2011, 65). Por ende, «las normas estatutarias son de carácter general, abstracto y permanente» (PACHECO 1993, 368) y establecen las «características identificadoras y las normas de funcionamiento básicas» (SENENT VIDAL 2011, 65). Estos tienen función constituyente para la cooperativa, puesto que son aprobados por los socios promotores y hacen parte de los documentos fundacionales.

Respecto a su contenido opera una distinción entre contenido de ley, contenido necesario y contenido complementario. «El contenido de ley es aquello que ya está en las normas legales y que se repite en 
un estatuto (...). El contenido necesario son aquellas normas que no están en la ley, pero la ley obliga a que se establezcan en el estatuto (...). [Y] El contenido complementario son todas las demás normas que cada entidad considere conveniente estipular» (GARCía MüLler 2017, 199, citando a CONFECOOP, 2003).

Como se infiere de esta clasificación, la presencia de determinados asuntos va a depender de su ubicación, en uno u otro tipo de contenido, según disponga el ordenamiento jurídico de que se trate.

Sin detrimento de lo expuesto, de la bibliografía consultada (CENZI, 2017; HENRŸ 2013; y SenENT VIDAL 2011) se pueden abstraer un conjunto de regularidades que -en una u otra condición - hacen parte de los Estatutos, a saber:

- Generales: denominación, duración, domicilio, ámbito geográfico y objeto.

- Miembros: requisitos, procedimiento de admisión, suspensión, exclusión y reintegro, obligaciones y derechos, renuncia/retiro, suspensión y exclusión y reintegro.

- Régimen disciplinario: tipos de faltas, sanciones, competencia, procedimiento, conciliación.

- Estructura organizativa: elementos comunes (Competencias, Procedimiento y condiciones de la convocatoria, Procedimiento para tomar decisiones, Documentación a emitir/custodiar e Impugnación); Asamblea General (clases y formas); y Órgano de Administración; Órgano de Control y otros órganos y comisiones/comités (representación legal, composición, elección, duración, cese, vacantes, funcionamiento, retribución, incompatibilidades, incapacidades y prohibiciones, y solución de conflictos).

- Régimen económico: responsabilidad de los miembros; capital social (aportaciones obligatorias y voluntarias, remuneración, actualización, transmisión, reembolso, aportes que no forman parte del capital, participaciones especiales, fondos y reservas, reserva legal, fondo legalmente dispuestos y fondos facultativos); y resultados (aplicación de excedentes e imputación de pérdidas).

- Régimen administrativo: ejercicio, documentación social, contabilidad, balance contable, estado de ganancias y pérdidas y otros.

— Disolución y liquidación: causales, adjudicación del haber social y extinción.

- Final: disposiciones generales y disposiciones transitorias.

Por su extensión y complejidad los Estatutos «pueden ser elaborados por el notario, por asesores profesionales (...) o, lo que es bastante 
común, por la propia Administración que facilita unos modelos orientativos» (GADEA, SACRISTÁn y VARGAS VASSEROt 2009, 122).

El complemento necesario del Estatuto, para superar la generalidad que a él es inmanente y proveer de funcionalidad a sus dictados es el Reglamento. Como parte del genus reglamentario este acto normativo interno deriva de la necesidad de disponer las regulaciones que se precisan para dar cumplimiento a una norma más general, asumiendo una finalidad ejecutiva (CAÑIZARES ABELEDo 2006, 223).

Según el grado de generalidad o la materia a que se refieran, pueden presentarse diversas tipologías de Reglamento. Es posible, entonces, encontrar disposiciones de esta naturaleza de carácter general para todos los socios o para ordenar una determinada actividad. El alcance que se pretenda con la regulación condicionará, unido a las disposiciones normativas más generales -Estatutos y leyes- el órgano facultado para su creación.

En cualquier caso, la forma que reviste el acto de adopción de esta decisión es el acuerdo. La fuerza vinculante de éste está condicionada a que su adopción se encuentre dentro de la esfera de competencia del órgano que los adopta y dicta, que su contenido no contradiga normas de rango superior, y que se sigan las formalidades correspondientes (GARCíA Müller 2017, 207).

El Reglamento Interno o de Régimen Interno es, desde el punto de vista jurídico, la variante más general que se puede asumir. Este se adopta por medio de un acuerdo de la asamblea general en el ejercicio de sus competencias (SENENT VIDAL 2005, 69) y su contenido lo deciden los socios en un puro ejercicio de auto-reglamentación, respetando el contenido de los Estatutos, las leyes y los principios cooperativos (GADEA, SACRISTÁn y VARgas VASSEROt 2009, 126).

Aunque la determinación de su contenido, dentro de los límites apuntado es libre, SENENT VIDAL $(2011,68-72)$ señala que entre sus contenidos más usuales figuran:

- Régimen jurídico de la persona socia: régimen disciplinario, prestación de trabajo de la persona socia y concretar el ejercicio de los derechos y deberes.

- Desarrollo del funcionamiento orgánico: regular el proceso electoral, funcionamiento de las sesiones, convocatorias, desarrollo de debates, ejercicio del derecho al voto, contenido y aprobación de actas, desarrollo de asambleas, juntas o comisiones espaciales e introducción de las TICs.

- Desarrollo de los aspectos económico-financieros: régimen de suscripción y desembolso de las distintas aportaciones al capital, 
sus formas de acreditar, su posible remuneración, actualización, transmisión y reembolso; las diversas modalidades de liquidación de las pérdidas del ejercicio, restantes vías de captación de financiamiento, dotación y aplicación de los fondos sociales, reservas voluntarias y fondo de educación y promoción.

- Medidas de responsabilidad social: creación y financiamiento de un Comité Social para ayudas y servicios a socios, trabajadores, sus familias, entre otros.

En cuanto a los Reglamentos particulares, García Müller sostiene que puede ser diversos, en tanto "se elaboran para regular actividades, servicios o departamentos» $(2017,205)$. Entre ellos puede encontrarse el del Consejo de Administración para «asegurarse de que su propio funcionamiento sea transparente» (HENRŸ 2013, 99). Tomando en cuenta la combinación entre el efecto ordenador del acto normativo y su contribución a una gestión democrática y transparente, es loable considerar su extensión al resto de los órganos y actividades de la cooperativa, por ser consustancial a la materialización de sus fines, de conformidad con su identidad.

Por medio de los acuerdos, los órganos competentes pueden elevar a la condición de jurídicas, previo cumplimiento de los requerimientos expuestos supra, un conjunto de normas ordenadoras de las distintas actividades que conciernen a la cooperativa. En este catálogo abierto se pueden incluir los manuales y sistemas de procedimiento, las normas técnicas, las regulae artis, y los códigos éticos o de conducta (GARCíA MüLler 2017, 212-214). Independientemente de las particularidades de cada uno de estos instrumentos regulatorios, lo relevante a los efectos del presente trabajo es evidenciar la amplitud de la facultad de autorregulación que, dentro del ámbito de la actividad propia de cada entidad, se encuentra a disposición de la misma en uso de una prerrogativa indiscutida como lo es la de adoptar acuerdos.

Por último, debe hacerse alusión a las normas individuales que, en virtud de la autonomía de la voluntad, crean y/o suscriben las cooperativas. En esta condición se encuentran los negocios jurídicos y las decisiones derivadas de los mecanismos de autocomposición interna ante conflictos.

El negocio jurídico puede considerarse como «una fuente formal del Derecho porque crea normas jurídicas individuales; es, por así decirlo, una ley particular que obliga a las personas que manifiestan su voluntad» (PACHECO 1993, 353). Esta afirmación es legítima si se asume que el acto jurídico en cuestión nace de actuaciones válidas y para perseguir fines jurídicamente posibles, con lo cual de él derivan obligacio- 
nes para las partes. Por ende, la lex contratus que resulta «es una ley autónoma, son preceptos que se da cada contratante, a tenor del compromiso que suscribe, vinculándose a una conducta» (Pérez Gallardo 2006, 318-319).

Dentro de esta categoría se encuentran comprendidos, a los efectos que aquí interesan, los contratos y los convenios. Los contratos suponen la composición de intereses por lo general contrapuestos, y sus obligaciones tienen carácter patrimonial, en tanto en el convenio concurren intereses confluyentes hacia una finalidad común a las partes, por lo cual no siempre se producen obligaciones de carácter patrimonial.

La eficacia obligatoria general de estos actos dependerá de que sean suscritos por el titular del órgano o responsabilidad competente dentro de la cooperativa. Nótese que, en tanto es persona jurídica, a la entidad solo pueden representarla y, en consecuencia, válidamente obligarla determinadas personas facultadas para ello.

Dada la naturaleza de la dinámica contractual, que supone el establecimiento de relaciones contra-prestacionales relativas al o a los objetos sociales acordados en el acto fundacional, es sencillo asumir que no precisa mayores autorizaciones o controles en tanto se consideran parte consustancial a la existencia misma de la asociación. En lo tocante a los convenios debe ocurrir otro tanto, aun cuando en el inconsciente colectivo pueden crearse aprehensiones o dudas, pues la armonización, complementación o articulación de finalidades implica asumir compromisos de naturaleza colaborativa o concurrente, pero siempre en correspondencia con los fines acordados.

La autocomposición de conflictos se caracteriza por permitir a las partes resolver una controversia sin necesidad de recurrir a la autoridad judicial, obteniendo una solución sobre la base de un acuerdo capaz de satisfacerlas. Lo relevante de los medios disponibles - mediación, conciliación y otros similares - al efecto que aquí interesa es que permite a las partes desempeñar un rol fundamental, pues son ellas mismas las que deciden y acuerdan la solución que tendrán controversias (FUENTES 2000 y García VilLALUENGA 2013). Al ser los protagonistas de la solución los litigantes, asumen la responsabilidad de sus propias decisiones obligándose a facilitar el cumplimiento voluntario del acuerdo (FonTE TelleRÍA 2017), operando entonces el mismo como norma auto-otorgada y aceptada.

Las cooperativas, aun cuando pueden recurrir a este tipo de procesos siempre que lo acuerden con la contraparte y no haya disposición en contrario, deben verse auto-compelidas a promover este tipo de procesos de manera preferente y previa a los métodos confrontaciones 
tradicionales para ventilar asuntos de trascendencia interna: cuando se susciten conflictos entre socios, entre los asociados y los órganos de la cooperativa. La razón para dar un trato particular a tales asuntos se sustenta en que en ambos casos se trata de situaciones que afectan el equilibrio societario.

Todas estas potencialidades contenidas en la facultad de auto-regulación - como parte del principio de autonomía - tienen una forma de expresión diferenciada según el ordenamiento jurídico las recepciones con mayor o menor amplitud. Ello no ha de suponer una restricción de sus contenidos, pues así se menoscabaría un elemento distintivo de la esencia de la cooperativa. Con esta convicción como guía, se ofrece seguidamente un análisis del nivel de desarrollo que ha tenido la aludida facultad en las normas cubanas que rigen para las CNA.

\section{Marco legal para la auto-regulación en las Cooperativas no Agropecuarias cubanas}

La autonomía cooperativa —en general - resulta una temática sensible en el contexto socialista cubano, pues su regulación jurídica está marcada por un modelo socioeconómico que concibe a la cooperativa con un rol subsidiario y altos niveles de dependencia/subordinación respecto al Estado (RodríGuez Musa, 2017). No obstante, el momento parece favorable para realizar valoraciones en este sentido, pues el país está inmerso en un proceso de actualización de su ordenamiento jurídico, tras la reciente proclamación de un nuevo texto constitucional.

A propósito, la Constitución cubana de 10 de abril de 2019, con una formulación más general que la de su predecesora, en tanto reconoce a la cooperativa sin limitarla a sectores concretos de la economía, advierte también que ella estará «sustentada en (...) el ejercicio efectivo de los principios del cooperativismo». Al respecto, téngase en cuenta que el ordenamiento jurídico socialista cubano nunca ha referido directamente los principios cooperativos enarbolados por la $\mathrm{ACl}$, ni tampoco ha utilizado un criterio uniforme para definirlos ${ }^{4}$. Por tanto, diversas podrán ser las interpretaciones que realice el legislador ordina-

4 Al respecto pueden compararse los preceptos de las diferentes leyes cooperativas del país, a saber: artículo 3 de la Ley No. 95/2002, «Ley de Cooperativas de Producción Agropecuaria y de Créditos y Servicios»; artículo 1 del Decreto-Ley 142/1993, "Sobre las Unidades Básicas de Producción Cooperativa» y artículo 4 del Decreto-Ley 305/2012, «De las Cooperativas no Agropecuarias». 
rio y la autoridad de aplicación sobre estos «principios» que ahora refiere el constituyente. En consecuencia, nada asegura que dicha interpretación incluirá la autonomía cooperativa, o que su implementación englobará los contenidos analizados supra.

Entre tanto, el Decreto-Ley 305 de 11 de diciembre de 2012, «De las Cooperativas no Agropecuarias» (DL305/12) y su complemento de igual fecha, el Decreto 309 «Reglamento de las Cooperativas no Agropecuarias de Primer Grado»(D309/12), fungen como la plataforma legal fundamental para estas formas asociativas, que con carácter experimental se manifiestan desde la aprobación de dichas normas en sectores de la economía como el trasporte, la industria, los servicios gastronómicos, etc.

La concepción que se asume en esta legislación sobre las CNA, en un principio parece coherente con la vocación de auto-regulación que debe caracterizar a la cooperativa, en tanto se prevé que se rijan, además de por las normas generales, por «sus estatutos» (artículo 3, DL305/12). Para sustentarlo, téngase en cuenta que se les define como una «organización» (artículo 2, apartado 1, DL305/12) con «...personalidad jurídica y patrimonio propio; [que] usa, disfruta y dispone de los bienes de su propiedad; cubre sus gastos con sus ingresos y responde de sus obligaciones con su patrimonio» (artículo 2, apartado 2, DL305/12). A tono con ello, entre los principios en que se sustentan se reconoce a la "Autonomía y sustentabilidad económica», que se define como sigue: "Las obligaciones se cubren con los ingresos. Pagados los tributos establecidos, crean los fondos y las utilidades se reparten entre sus socios en proporción a su contribución al trabajo» (artículo 4, inciso d), DL305/12).

Sin embargo, desde estas definiciones - que no retoma el Reglamento general - ya parece despuntar un criterio economicista sobre estas formas de gestión que podría reducir sustancialmente el ejercicio integral de su autonomía. Ante esta dificultad, la auto-regulación de las CNA puede ser decisiva en la realización de los «fines económicos y sociales» de la institución, así como en la «satisfacción del interés social y el de los socios» (artículo 2, DL305/12). Por tanto, toca preguntarse qué espacio ofrece para este propósito la legislación que las regula.

Al respecto destaca el artículo 21 del D309/12, donde se reglamen$\tan 19$ aspectos que deben contener los Estatutos de las CNA, lo cual ha contribuido a que este cuerpo normativo interno se sobrecargue de contenidos, procedimientos y reglas detalladas que - como tal- requieren modificación frecuente, con sus inevitables costes en tiempo y dinero. 
Este tono reglamentista del legislador, se potencia cuando el artículo 11 exige la intervención de la Administración Pública en la aprobación de varios contenidos trascendentales para el funcionamiento de la cooperativa, en tanto el órgano u organismo del Estado a quien corresponde autorizar la constitución de la cooperativa (según el artículo 3 del D309/12), en el mismo acto aprueba su objeto social; el tipo de moneda en que operará; el nombre de las personas solicitantes; el inmueble y otros bienes a ceder, así como las condiciones en las que se realizará esta cesión. También aprueba los bienes o servicios que constituyen el pedido del Estado; los principales insumos a suministrar por el proveedor estatal y los precios de bienes y servicios que se mantendrán centralmente establecidos.

Teniendo en cuenta que varios de estos aspectos coinciden -total o parcialmente- con los contenidos - mínimos - que deben incluir los Estatutos según el referido artículo 21, podría convertirse la voluntad de la Administración Pública en un muro de contención que dificulte la realización de la autonomía de la cooperativa (Vid. Anexo). No obstante, vale resaltar que los órganos locales del Poder Popular, organismos o entidades nacionales realizan, de conjunto con el representante o el Comité Gestor de la Cooperativa en Formación, evaluaciones y negociaciones previas respecto a varios asuntos que condicionan el contenido de los Estatutos (D309/12, artículo 9). Por tanto, la defensa del justo equilibro entre la autonomía cooperativa y su responsabilidad social puede y debe comenzar desde esta etapa (Vid. Anexo).

Además, cuando se observa que el resto del articulado que rige a las CNA en la legislación referida toca — de una u otra forma - todos los contenidos reglamentarios de los Estatutos, mediante normas generalmente de carácter preceptivo (Vid. Anexo), podría pensarse que poco puede hacerse en favor de la auto-regulación de las CNA. Sin embargo, un análisis detallado de esta normativa, permite apreciar que, en múltiples ocasiones, el legislador tan solo orienta o prevé mínimos indispensables, reservando un espacio — más o menos flexible- para los Estatutos, cuya óptima realización depende de la iniciativa y voluntad de los asociados.

En este sentido, merecen especial mención cuestiones tales como el domicilio social; la cantidad mínima y máxima de socios; los requisitos para asociarse; los derechos y deberes que le otorga este vínculo; el monto al que asciende el aporte de cada uno al capital de trabajo; las causas que pueden ocasionar la pérdida de esa condición; las reglas para la distribución de utilidades; el destino de los fondos; las premisas para la comercialización de sus producciones después de cubiertos los 
compromisos reglamentarios; las personas facultadas para abrir y operar las cuentas bancarias; el sistema de retribución; el procedimiento para aplicar medidas disciplinarias a los socios; el régimen de los trabajadores eventuales; etc.

Por último, las Indicaciones Metodológicas del 10 de junio de 2013, de la Dirección de los Registros de la Propiedad, Mercantil y Patrimonio del Ministerio de Justicia (Ind.Metod.MINJUS/13), advierten que -además de las generales respecto a la autorización y escritura de constitución - son "circunstancias de obligatoria inscripción» para la CNA, nueve (9) de los aspectos reglamentarios que deben contener los Estatutos (Vid. Anexo). Teniendo en cuenta que «la Cooperativa No Agropecuaria de Primer Grado adquiere su personalidad jurídica a partir de su inscripción en el Registro Mercantil», y que su «...publicidad, se hará efectiva mediante Certificación, siendo este el único medio de acreditar el contenido de los asientos del Registro y, en consecuencia, constituye prueba fehaciente para dar comienzo a sus operaciones», la CNA debe reforzar la atención a estos aspectos antes, durante y después de su proceso de constitución.

Definidos los marcos legales a partir de los cuales las cooperativas objeto de estudio pueden concretar su autonomía de regulación, se argumentarán a continuación un grupo de presupuestos destinados a contribuir, mediante la asesoría jurídica, al logro de este propósito.

\section{Perfeccionamiento de la auto-regulación en las Cooperativas no Agropecuarias mediante la asesoría jurídica}

Como se ha venido sosteniendo, una actividad complementaria al desarrollo cooperativo como la asesoría jurídica, resulta esencial a los efectos de encausar los esfuerzos dirigidos hacia una auto-ordenación coherente con el sistema normativo vigente, así como con las necesidades de la entidad en cuestión. La relevancia de optimizar el asesoramiento obedece a que las acciones que el jurista/asesor/consultor realiza tienen reflejo directo en la forma en que proyecta el ente cooperativo. Tómese en cuenta que este es el responsable de confeccionar o actualizar los documentos que constituyen la base legal de la entidad; orientar y/o responder consultas al representante legal y a otros directivos u órganos del sujeto asesorado; redactar o asistir en la redacción de los instrumentos jurídicos y otros documentos; y representar legalmente a la organización ante el órgano administrativo autorizante, las instancias jurisdiccionales, los registros y demás oficinas del Estado (UPR-EPSEL, 2019). 
Por tal motivo, el estudio de la reorganización del proceso de asesoramiento debe sustentarse en referentes teóricos precisos que permitan procurar una clara delimitación de las formas, alcances y contenidos que pueden asumir las actuaciones de las cooperativas en su auto-regulación. Sobre este particular, ha de precisarse que, en virtud del principio de autonomía, la capacidad para auto-ordenarse tiene eficacia transversal, asumiendo que los únicos límites admisibles para ella serían el respeto por la identidad cooperativa y la legalidad, dado que se opera dentro de un esquema que pondera la subsidiariedad en beneficio de estas formas asociativas.

En este sentido vale recordar que el Código Civil Cubano de 1987 (CCC) no se refiere directamente a las CNA, pero las disposiciones generales de este cuerpo normativo "....son supletorias respecto a materias civiles $u$ otras reguladas en leyes especiales» (artículo 8, CCC). Por tanto, en los instrumentos que determinan el régimen jurídico interno de estas entidades sobre la base del acuerdo de sus miembros, «...las partes pueden establecer los pactos, cláusulas y condiciones que tengan por conveniente, salvo disposición legal en contrario» (artículo 312, CCC).

Lo antes referido ha de incluirse, junto a algunas otras directivas, en la «Metodología para el Trabajo de los Consultores Jurídicos en el sector Cooperativo», a fin de que ésta cumpla el propósito de optimizar el asesoramiento legal a las CNA. Ello ha de ir acompañado de una orientación que permita la adecuada selección de los instrumentos legales idóneos para cada tipología de actuación de la cooperativa, ya sea en la esfera interna - relativa a las relaciones entre socios y la organización/funcionamiento de la entidad - como externa — atinente a su vinculación e interacción con los restantes actores del tráfico jurídico-.

En cualquier caso, las reglas que guíen la actuación del jurista encargado de asesorarlas, deben tomar en consideración que las necesidades de cada CNA son diferentes, y que el carácter de cada disposición jurídica es singular. En consecuencia, resulta imprescindible el ejercicio de procurar la correspondencia entre uno y otro elemento, sobre la base de una clara determinación del nivel de autonomía que permite el ordenamiento general.

En primera instancia, debe tomarse conciencia de que existen elementos que el Reglamento general no exige se incluyan en los Estatutos de las CNA cubanas. Estos constituyen una reserva que podrían contribuir a potenciar la identidad cooperativa en el funcionamiento de estas formas asociativas.

No obstante, tal regulación no tiene que ser objeto de los Estatutos, o al menos no hasta agotar su contenido, sino que pueden lle- 
varse a un Reglamento de Régimen Interno (RRI), cuya utilización en Cuba - como regla - es inexistente. Esta recomendación obedece a la dificultad añadida que implica la modificación estatutaria y la flexibilidad que ofrece - en contraste- el RRI.

Dicho Reglamento tiene una naturaleza asimilable a la de los acuerdos asamblearios, en tanto rigen — principalmente - la vida interna de la cooperativa y su aprobación correspondería a la Asamblea General, por lo que su utilización es aceptable dentro del marco legal vigente en el país, vinculando a todos los socios. Su única diferencia reseñable respecto a los demás acuerdos estribaría en la obligación del órgano correspondiente de la cooperativa, de entregar copia de ellos a los asociados (GADEA, SACRISTÁN y VARGAS VASSEROt 2009, 126-127). De su existencia se dejaría constancia en un documento privado, que se incorporaría al Acta de la Asamblea General donde fue aprobado, pudiendo adquirir publicidad por medio de la certificación del acuerdo que lo contiene (artículo 39, inciso d., D309/12), aspecto relevante para respaldar intereses legítimos de terceros.

Este instrumento jurídico, dada la relativa generalidad de sus dictados, puede servir para desarrollar un grupo importante de aspectos del desenvolvimiento cooperativo que guardan correspondencia directa con su identidad y que a apenas se mencionan en las normas legales que regulan el sector.

Dentro de las cuestiones que podrían encontrar salida por tal vía figuran, entre otras, el funcionamiento de los órganos de las CNA, a fin de proveer seguridad jurídica y transparencia a su gestión democrática. Las debilidades presentes en las normas vigentes al respecto, ya han sido tratadas en investigaciones precedentes por PIÑEIRO HARNECKER (2016) y MESA TEJEDA (2014). De conformidad con los resultados de tales estudios, es recomendable que la auto-regulación se enfoque en suplir las carencias existentes, uniformando los términos de convocatorias a reuniones y de suspensión de estas (artículo 34, D309/12); esclareciendo las reglas sobre las rendiciones de cuentas; definiendo las atribuciones de la Junta Directiva (artículo 45, D309/12); ponderando en su justa medida las funciones del Presidente, de manera que sean coherentes con la supremacía de la Asamblea General; etc.

Respecto a la organización de actividades consustanciales a la esencia cooperativa, como la educación, el enfoque de género, la vinculación a lo local y la responsabilidad social, también se han fundamentado propuestas concretas (Rodríguez MuSA 2017, 146-151). Algunas de estas ideas descansan en asumir conceptos más participativos, que sustituyan «capacitación» por "acompañamiento» e «incubación» de conjunto con las universidades. De igual forma, se requiere involucrar 
a las CNA en la planificación de la economía desde el territorio, con la mira no solo en el Plan Nacional, sino también en las necesidades de la comunidad en que se inserta. En este mismo sentido, vale resaltar la pertinencia de asumir modelos de gestión de la responsabilidad social cooperativa, que tiendan a la intervención directa de ésta en la comunidad.

Para contribuir a la concreción de estos aspectos, la CNA puede facultar a alguno de sus órganos de la ejecución y control, priorizarlo en el Plan anual interno, así como asignarle fondos concretos, todo lo cual depende esencialmente de la voluntad de sus socios y, como tal, puede auto-organizarse.

Otra potencialidad del enfoque holístico de la autorregulación radica en que puede servir como un medio para apoyar el establecimiento de compromisos con otros actores, a fin de encausar legalmente el establecimiento de convenios de colaboración válidos con otras entidades de igual naturaleza, dando pasos concretos hacia la cooperación entre cooperativas. Además, sería instrumento apropiado para incidir en la regulación de los medios alternativos de solución de conflictos. Nótese al respecto, que el Capítulo VII del D309/12 se ocupa en exclusiva de los conflictos que surjan entre los socios y la CNA, dejando sin tratamiento a las posibles discrepancias que se susciten entre estas formas asociativas y los demás actores jurídicos. Respecto a este particular, el acuerdo entre las partes en disputa tendría el valor de surtir efectos vinculantes entre ellas, supliendo así la carencia de las normas generales.

\section{Conclusiones}

1. Al amparo del principio de autonomía, las cooperativas gozan de la facultad de auto-regulación, en correspondencia con su identidad y en los límites que delinean el respeto por la legalidad y la subsidiariedad. Dentro de tales marcos están a disposición de estas organizaciones un abanico de instrumentos jurídicos — generales y particularesque les permiten optar — con cierta libertad - por el que resulte más idóneo según las características de las situaciones concretas de que se trate.

2. La auto-regulación de las CNA puede ser decisiva en la "satisfacción del interés social y el de los socios», así como en la realización de los «fines económicos y sociales» de la institución. Al respecto se reglamentan varios aspectos que deben contener los Estatutos de las CNA, lo cual ha contribuido a que este cuerpo normativo interno se so- 
brecargue. No obstante, un análisis detallado de la normativa general que las rige, permite apreciar que, en múltiples ocasiones, el legislador tan solo orienta o prevé mínimos indispensables, reservando un espacio - más o menos flexible- para los Estatutos, cuya óptima realización depende de la voluntad de los asociados.

3. La asesoría jurídica como actividad complementaria al desarroIlo de las CNA en Cuba, cuenta con reservas significativas a desarrollar en el plano de la autorregulación cooperativa. Entre ellas destacan la posibilidad de suplir carencias de las normas generales a través de los Estatutos y del RRI, en los marcos de la legalidad que complementa el CCC. De esta forma, pueden celebrar válidamente acuerdos con otros actores, dando cauce a relaciones que incluyan vínculos de cooperación con instituciones de diversa naturaleza, especialmente con otras cooperativas, así como a pactos para la solución conciliada de conflictos.

\section{Bibliografía}

1. CALLOWAY, C. 2016. "Autorregulación de colectivos autogestión de trabajadores/as». Revista del IDELCOOP, 218. Buenos Aires: Ediciones IDELCOOP.

2. CAÑIZARES ABELEDO, D.F. 2006. "Acerca de la facultad reglamentaria de la Administración Estatal». Temas de Derecho Administrativo cubano. Tomo 1. Colectivo de autores. La Habana: Editorial Félix Varela.

3. CENZI, N.L. 2017. "Los estatutos de la cooperativa. Elaboración. Cuidados. El papel del asesor jurídico en su elaboración y modificación». I Taller Internacional de Derecho Cooperativo. Pinar del Río, 1, 2 y 3 de marzo.

4. COODER. 2018. Relatoría del II Taller Internacional de Derecho Cooperativo. Pinar del Río: Universidad de Pinar del Río.

5. CRACOGNA, D. 2001. La legislación cooperativa en el mundo de hoy. Presentado en el Seminario de legislación cooperativa en Uruguay, el 22 de noviembre. Consultado en http://www.neticoop.org.uy/article118.html, el 13 de mayo de 2010.

6. FAJARDO GARCÍA, G. y MORENO CRUZ, M. 2018 (coordinadoras): «EI cooperativismo en Cuba. Situación actual y propuestas para su regulación y fomento». Valencia: CIRIEC-España.

7. FERNÁNDEZ BULTÉ, J. 2004.Teoría del Estado y el Derecho. T. II. Teoría del Derecho. La Habana: Editorial Félix Varela.

8. FERNÁNDEZ PEISO, A. 2006. Lecturas en pro del cooperativismo, ante las imprescindibles transformaciones económicas del socialismo cubano. Cienfuegos: Universo Sur.

9. FONTE TELLERÍA, A.L. 2017. La mediación como medio alternativo de solución de conflictos en Cuba. Fundamentos para su adecuada regulación 
jurídica. Tesis en opción al título de Licenciado en Derecho. Pinar del Río: Universidad de Pinar del Río.

10. FROSINI, T.E. 2002. "Subsidiariedad y Constitución». Revista de Estudios Políticos, 115.

11. FUENTES, M. 2000. Mediación en la Solución de Conflictos. Primera Edición. La Habana: Félix Varela.

12. GADEA, E.; SACRISTÁN, F. y VARGAS VASSEROT, C. 2009. Régimen jurídico de la sociedad cooperativa del siglo XXI. Realidad actual y propuestas de reforma. Madrid: Editorial Dykinson S.L.

13. GARCÍA MÜLLER, A. 2006. Instituciones de Derecho Cooperativo, Social, Solidario o de Participación. Mérida.

14. GARCÍA MÜLLER, A. 2017. Derecho cooperativo y de la Economía Social y Solidaria. Mérida - Bogotá: Asociación Iberoamericana de Derecho Cooperativo, Mutual y de la Economía Social y Solidaria.

15. GARCÍA VILLALUENGA, L. 2003. «Formación y profesionalización del mediador familiar: realidades y expectativas». Revista Área Social. 3. Castillas-La Mancha: Edición Colegio Oficial de Diplomados en Trabajo Social y Asistentes Sociales de Castilla-La Mancha.

16. HENRŸ, H. 2000. Cuadernos de Legislación Cooperativa. Ginebra: OIT. Recuperado de www.redelaldia.org/IMG/pdf/0105.pdf, el 3 de mayo de 2013.

17. HENRŸ, H. 2013. Orientaciones para la legislación cooperativa. Segunda Edición. Ginebra: OIT.

18. MESA MEJÍAS, M.P. 2019. "Las relaciones entre los sujetos del sector no estatal cubano: el socio-Trabajador por Cuenta Propia en las Cooperativas No Agropecuarias». Boletín de la Asociación Internacional de Derecho Cooperativo, 54: 131-144. doi: http://dx.doi.org/10.18543/baidc-542019pp131-144

19. MESA TEJEDA, N.T. 2014. «Reflexiones críticas en torno a la regulación de las cooperativas no agropecuarias en Cuba». Boletín de la Asociación Internacional de Derecho Cooperativo, 48: 227-243. doi: http://dx.doi. org/10.18543/baidc-48-2014pp227-243

20. MESA TEJEDA, N.T. y HERNÁNDEZ ATIENZA, M.K. 2017. «Reflexiones en torno al régimen de solución de conflictos en las cooperativas no agropecuarias de Cuba». Boletín de la Asociación Internacional de Derecho Cooperativo, 51: 243-259. doi: http://dx.doi.org/10.18543/baidc-512017pp243-259

21. ORGANIZACIÓN INTERNACIONAL DEL TRABAJO. 2002. Recomendación 193, «Promoción de las Cooperativas». Ginebra: OIT.

22. PACHECO, M. 1993. Teoría del Derecho. Cuarta Edición. Santiago de Chile: Editorial Jurídica de Chile.

23. PÉREZ GALLARDO, L.B. 2006. «De la eficacia contractual. I. Principios generales». Derecho de Contratos. Teoría General del Contrato. T. I. OJEDA RODRÍGUEZ, N. (compiladora). La Habana: Editorial Félix Varela.

24. PIÑEIRO HARNECKER, C. 2016. Diagnóstico preliminar de las cooperativas no agropecuarias en La Habana, Cuba. Recuperado de https://www.ceec. uh.cu/file/569/download?token=VfqEKMZE, el 18 de abril de 2016. 
25. RODRÍGUEZ MUSA, O. 2013. «La autonomía cooperativa y su expresión jurídica. Una aproximación crítica a su actual implementación legal en Cuba». Boletín de la Asociación Internacional de Derecho Cooperativo. 47: 129-156. doi: http://dx.doi.org/10.18543/baidc-47-2013pp129-156.

26. RODRÍGUEZ MUSA, O. 2017. La constitucionalización de la cooperativa. Una propuesta para su redimensionamiento en Cuba. Brasilia-DF: Editorial Vincere Asociados. Coletânea IBECOOP, No. 1.

27. RODRÍGUEZ MUSA, O. y HERNÁNDEZ AGUILAR, O. (coordinadores). 2018a). Apuntes de Derecho Cooperativo para Cuba. Pinar del Río: Ediciones Loynaz.

28. RODRÍGUEZ MUSA, O. y HERNÁNDEZ AGUILAR, O. 2018 b). «La concepción societaria del Derecho Romano como referente para el perfeccionamiento de la regulación de la cooperativa en Cuba». Revista Deusto Estudios Cooperativos. 11.

29. ROSEMBURG, T. 1985. La Empresa Cooperativa. Barcelona: Editorial CEAC.

30. SENENT VIDAL, M. ${ }^{\text {J }}$. 2005. «El reglamento de régimen interno de la cooperativa: «Instrucciones de uso». Revista Jurídica de la Economía Social y Cooperativa. 16.

31. SENENT VIDAL, M.J. 2011. "Estatutos sociales y otros documentos». Cooperativas: régimen jurídico y fiscal». FAJARDO GARCíA, G. (coordinadora). Valencia: Tirant lo Blanch.

32. SOTO, L. 2017. «Notas en pos de la regulación jurídica del balance social cooperativo en Cuba». Boletín de la Asociación Internacional de Derecho Cooperativo, 51: 317-344. doi: http://dx.doi.org/10.18543/baidc-512017pp317-344.

33. UNIVERSIDAD DE PINAR DEL RÍO (UPR)-EMPRESA PROVINCIAL DE SERVICIOS LEGALES (EPSEL) 2018. Informe de Resultados parciales del Proyecto de Investigación «Metodología para perfeccionar el proceso de asesoría jurídica a las Cooperativas no Agropecuarias de la provincia de Pinar del Río», a desarrollarse entre los años 2018 y 2022.

\section{Legislación}

1. CONSTITUCIÓN DE LA REPÚBLICA DE CUBA. Gaceta Oficial Extraordinaria No. 5. 10 de abril de 2019.

2. LEY No. 59. «Código Civil» cubano. Gaceta Oficial Extraordinaria No. 9. 15 de octubre de 1987.

3. LEY No. 95 «Ley de Cooperativas de Producción Agropecuaria y de Créditos y Servicios». Gaceta Oficial Ordinaria No. 72. 29 de noviembre de 2002.

4. DECRETO-LEY No. 305. «De las cooperativas no agropecuarias». Gaceta Oficial No. Extraordinaria 053. 11 de diciembre de 2012.

5. DECRETO No. 309. «Reglamento de las Cooperativas No Agropecuarias de Primer Grado», Gaceta Oficial Extraordinaria No. 053. 11 de diciembre de 2012. 


\section{Anexo. Contenidos de los Estatutos de las Cooperativas No Agropecuarias cubanas}

\begin{tabular}{|c|c|c|c|c|}
\hline $\begin{array}{l}\text { Contenidos necesarios o } \\
\text { reglamentarios } \\
\text { (D309/12, artículo 21) }\end{array}$ & $\begin{array}{c}\text { Requeridos } \\
\text { de evaluaciones } \\
\text { y negociaciones } \\
\text { previas } \\
\text { (D309/12, artículo 9) }\end{array}$ & $\begin{array}{c}\text { Requeridos } \\
\text { de aprobación } \\
\text { administrativa previa } \\
\text { (D309/12, } \\
\text { artículo 11) }\end{array}$ & $\begin{array}{l}\text { Carácter de otras } \\
\text { regulaciones que les atañan } \\
\text { (DL305/12 y D309/12) }\end{array}$ & $\begin{array}{c}\text { Circunstancias de } \\
\text { obligatoria inscripción } \\
\text { en el Registro Mercantil } \\
\text { (Ind.Metod.MINJUS/13) }\end{array}$ \\
\hline $\begin{array}{l}\text { a) La denominación } \\
\text { completa y, en su } \\
\text { caso, abreviada. }\end{array}$ & NO & $\begin{array}{l}\text { b) Denominación de } \\
\text { la Cooperativa, } \\
\text { que deberá incluir } \\
\text { el vocablo «Coo- } \\
\text { perativa». }\end{array}$ & $\begin{array}{l}\text { D309/12, artículo } 17 . \\
\text { — Preceptúa que se con- } \\
\text { signe en la Escritura } \\
\text { notarial de constitu- } \\
\text { ción. }\end{array}$ & $\begin{array}{l}\text { 1. La denomina- } \\
\text { ción completa y, } \\
\text { en su caso abre- } \\
\text { viada. }\end{array}$ \\
\hline b) La duración. & NO & NO & NO & 2. La duración. \\
\hline c) El objeto social. & $\begin{array}{l}\text { a) Posible ob- } \\
\text { jeto social. }\end{array}$ & $\begin{array}{l}\text { a) El objeto social } \\
\text { que se autoriza... }\end{array}$ & $\begin{array}{l}\text { D309/12, artículos } 14 \text { y } \\
15 . \\
\text { — Indicación sobre qué } \\
\text { entender por objeto } \\
\text { social. } \\
\text { - Preceptúa sobre el } \\
\text { uso comercial de este } \\
\text { cuando se encuentre } \\
\text { registrado. }\end{array}$ & 3. El objeto social. \\
\hline NO & $\begin{array}{l}\text { j) El impacto } \\
\text { ambiental. }\end{array}$ & NO & $\begin{array}{l}\text { f) Los planes de las } \\
\text { cooperativas tienen } \\
\text { como objetivo contri- } \\
\text { buir al desarrollo eco- } \\
\text { nómico y social sos- } \\
\text { tenible de la nación, } \\
\text { proteger el medio } \\
\text { ambiente, desarro- } \\
\text { Ilar sus actividades sin } \\
\text { ánimo especulativo y } \\
\text { garantizar el cumpli- } \\
\text { miento disciplinado } \\
\text { de las obligaciones } \\
\text { fiscales y otras. } \\
\text { Trabajan por fomentar la } \\
\text { cultura cooperativista y } \\
\text { por las satisfacciones de } \\
\text { las necesidades materia- } \\
\text { les, de capacitación, so- } \\
\text { ciales, culturales, morales } \\
\text { y espirituales de sus so- } \\
\text { cios y familiares. }\end{array}$ & NO \\
\hline
\end{tabular}




\begin{tabular}{|c|c|c|c|c|}
\hline $\begin{array}{l}\text { Contenidos necesarios o } \\
\text { reglamentarios } \\
\text { (D309/12, artículo 21) }\end{array}$ & $\begin{array}{c}\text { Requeridos } \\
\text { de evaluaciones } \\
\text { y negociaciones } \\
\text { previas } \\
\text { (D309/12, artículo 9) }\end{array}$ & $\begin{array}{c}\text { Requeridos } \\
\text { de aprobación } \\
\text { administrativa previa } \\
\text { (D309/12, } \\
\text { artículo 11) }\end{array}$ & $\begin{array}{l}\text { Carácter de otras } \\
\text { regulaciones que les atañan } \\
\text { (DL305/12 y D309/12) }\end{array}$ & $\begin{array}{c}\text { Circunstancias de } \\
\text { obligatoria inscripción } \\
\text { en el Registro Mercantil } \\
\text { (Ind.Metod.MINJUS/13) }\end{array}$ \\
\hline $\begin{array}{l}\text { d) El domicilio so- } \\
\text { cial, con expre- } \\
\text { sión de la direc- } \\
\text { ción exacta. }\end{array}$ & NO & NO & NO & $\begin{array}{l}\text { 4. El domicilio so- } \\
\text { cial, con expre- } \\
\text { sión de la direc- } \\
\text { ción exacta. }\end{array}$ \\
\hline $\begin{array}{l}\text { e) La cantidad mí- } \\
\text { nima y máxima } \\
\text { de socios, si se } \\
\text { entiende preciso } \\
\text { fijar uno u otro } \\
\text { de esos límites, o } \\
\text { ambos. }\end{array}$ & NO & NO & NO & $\begin{array}{l}\text { 5. La cantidad mí- } \\
\text { nima y máxima } \\
\text { de socios, si se } \\
\text { entiende preciso } \\
\text { fijar uno u otro } \\
\text { de esos límites, o } \\
\text { ambos. }\end{array}$ \\
\hline $\begin{array}{l}\text { f) Los requisitos } \\
\text { para ser socio. }\end{array}$ & NO & $\begin{array}{l}\text { c) Nombre de las } \\
\text { personas solici- } \\
\text { tantes y de su re- } \\
\text { presentante. }\end{array}$ & $\begin{array}{l}\text { DL 305/12, artículo } 10, \\
\text { y D309/12, artículos } 26 \\
\text { y } 27 . \\
\text { - Preceptúa mínimos } \\
\text { sobre edad, residencia } \\
\text { y capacidad. } \\
\text { - Preceptúa la prefe- } \\
\text { rencia para ser socios } \\
\text { fundadores de los tra- } \\
\text { bajadores de las en- } \\
\text { tidades estatales que } \\
\text { pasa a gestión coope- } \\
\text { rativa. } \\
\text { - Establece mínimos } \\
\text { formales del procedi- } \\
\text { miento de incorpora- } \\
\text { ción a la CNA de otros } \\
\text { socios, donde se favo- } \\
\text { rece la decisión de la } \\
\text { Asamblea General. }\end{array}$ & $\begin{array}{l}\text { 6. La identidad de } \\
\text { cada socio... }\end{array}$ \\
\hline $\begin{array}{l}\text { g) Los derechos y } \\
\text { deberes generales } \\
\text { de los socios. }\end{array}$ & NO & NO & $\begin{array}{l}\text { D 309/12, artículos } 28 \text { y } \\
29 \text {. } \\
\text { — Preceptúa algunos de- } \\
\text { rechos ( } 7 \text { incisos) y de- } \\
\text { beres ( } 5 \text { incisos), sin } \\
\text { perjuicio de otros que } \\
\text { puedan prever los Es- } \\
\text { tatutos. }\end{array}$ & NO \\
\hline
\end{tabular}




\begin{tabular}{|c|c|c|c|c|}
\hline $\begin{array}{l}\text { Contenidos necesarios o } \\
\text { reglamentarios } \\
\text { (D309/12, artículo 21) }\end{array}$ & $\begin{array}{c}\text { Requeridos } \\
\text { de evaluaciones } \\
\text { y negociaciones } \\
\text { previas } \\
\text { (D309/12, artículo 9) }\end{array}$ & $\begin{array}{c}\text { Requeridos } \\
\text { de aprobación } \\
\text { administrativa previa } \\
\text { (D309/12, } \\
\text { artículo 11) }\end{array}$ & $\begin{array}{l}\text { Carácter de otras } \\
\text { regulaciones que les atañan } \\
\text { (DL305/12 y D309/12) }\end{array}$ & $\begin{array}{c}\text { Circunstancias de } \\
\text { obligatoria inscripción } \\
\text { en el Registro Mercantil } \\
\text { (Ind.Metod.MINJUS/13) }\end{array}$ \\
\hline $\begin{array}{l}\text { h) El monto del } \\
\text { aporte dinerario } \\
\text { de cada socio al } \\
\text { capital de trabajo. }\end{array}$ & NO & NO & $\begin{array}{l}\text { D309/12, artículos } 46 \text { al } \\
51 . \\
\text { - Disposiciones orienta- } \\
\text { doras generales sobre } \\
\text { el procedimiento. No } \\
\text { se define el monto de } \\
\text { capital. }\end{array}$ & $\begin{array}{l}\text { 6. ...el monto del } \\
\text { aporte dinerario } \\
\text { o de otra natura- } \\
\text { leza al capital de } \\
\text { trabajo. }\end{array}$ \\
\hline $\begin{array}{l}\text { i) Las causas que } \\
\text { ocasionan la pér- } \\
\text { dida de la condi- } \\
\text { ción de socio. }\end{array}$ & NO & NO & $\begin{array}{l}\text { D 309/12, artículos } 30 \text { al } \\
32 . \\
\text { - Preceptúa causales } \\
\text { básicas (5 incisos), sin } \\
\text { perjuicio de otras que } \\
\text { puedan prever los Es- } \\
\text { tatutos. Protege los } \\
\text { derechos económicos } \\
\text { del socio saliente en } \\
\text { vida y por causa de } \\
\text { muerte. }\end{array}$ & NO \\
\hline $\begin{array}{l}\text { j) Los órganos de } \\
\text { dirección y de ad- } \\
\text { ministración, su } \\
\text { competencia y } \\
\text { las reglas básicas } \\
\text { de su funciona- } \\
\text { miento. }\end{array}$ & NO & NO & $\begin{array}{l}\text { DL305/12, artículos } 17 \text { al } \\
19, \text { y D 309/12, artícu- } \\
\text { los } 33 \text { al } 45 \text {. } \\
\text { - Normativa amplia y } \\
\text { detallada, con predo- } \\
\text { minio del tono pre- } \\
\text { ceptivo y poco espa- } \\
\text { cio para la regulación } \\
\text { interna de la CNA. }\end{array}$ & $\begin{array}{l}\text { 8. Los órganos de } \\
\text { dirección y de } \\
\text { administración, } \\
\text { así como las per- } \\
\text { sonas que ocu- } \\
\text { pan cargos den- } \\
\text { tro de estos } \\
\text { órganos y su } \\
\text { competencia. }\end{array}$ \\
\hline
\end{tabular}




\begin{tabular}{|c|c|c|c|c|}
\hline $\begin{array}{l}\text { Contenidos necesarios o } \\
\text { reglamentarios } \\
\text { (D309/12, artículo 21) }\end{array}$ & $\begin{array}{c}\text { Requeridos } \\
\text { de evaluaciones } \\
\text { y negociaciones } \\
\text { previas } \\
\text { (D309/12, artículo 9) }\end{array}$ & $\begin{array}{c}\text { Requeridos } \\
\text { de aprobación } \\
\text { administrativa previa } \\
\text { (D309/12, } \\
\text { artículo 11) }\end{array}$ & $\begin{array}{l}\text { Carácter de otras } \\
\text { regulaciones que les atañan } \\
\text { (DL305/12 y D309/12) }\end{array}$ & $\begin{array}{c}\text { Circunstancias de } \\
\text { obligatoria inscripción } \\
\text { en el Registro Mercantil } \\
\text { (Ind.Metod.MINJUS/13) }\end{array}$ \\
\hline $\begin{array}{l}\text { k) El régimen eco- } \\
\text { nómico-finan- } \\
\text { ciero, en el cual } \\
\text { se incluye, entre } \\
\text { otros aspectos so- } \\
\text { bre el patrimonio, } \\
\text { - los límites y } \\
\text { formas de dis- } \\
\text { posición de los } \\
\text { bienes y dere- } \\
\text { chos que lo in- } \\
\text { tegran, }\end{array}$ & $\begin{array}{l}\text { b) Diseño finan- } \\
\text { ciero. } \\
\text { c) Inmuebles y } \\
\text { otros bienes a } \\
\text { arrendar. } \\
\text { d) Medios, uten- } \\
\text { silios y he- } \\
\text { rramientas a } \\
\text { vender. } \\
\text { h) Si procede, la } \\
\text { determinación } \\
\text { del período } \\
\text { de exonera- } \\
\text { ción del pago } \\
\text { del arrenda- } \\
\text { miento. } \\
\text { k) El cumpli- } \\
\text { miento de } \\
\text { normas y re- } \\
\text { gulaciones } \\
\text { sobre el or- } \\
\text { denamiento } \\
\text { territorial. }\end{array}$ & $\begin{array}{l}\text { d) Inmuebles y otros } \\
\text { bienes a arren- } \\
\text { dar o ceder en } \\
\text { usufructo u otra } \\
\text { forma legal que } \\
\text { no implique la } \\
\text { transmisión de } \\
\text { la propiedad, } \\
\text { cuando corres- } \\
\text { ponda. } \\
\text { e) Período por el } \\
\text { cual se va a exo- } \\
\text { nerar del pago del } \\
\text { arrendamiento, si } \\
\text { procede. } \\
\text { f) Medios, utensilios } \\
\text { y herramientas a } \\
\text { vender, cuando } \\
\text { corresponda. }\end{array}$ & $\begin{array}{l}\text { DL305/12, artículo 7, y } \\
\text { D309/12, artículo } 12 \text {. } \\
\text { — Fija el término } \\
\text { máximo del arrenda- } \\
\text { miento, del usufructo } \\
\text { u otras formas legales } \\
\text { que no impliquen la } \\
\text { transmisión de la pro- } \\
\text { piedad a la coopera- } \\
\text { tiva, prorrogables por } \\
\text { igual término en pe- } \\
\text { ríodos sucesivos. }\end{array}$ & NO \\
\hline $\begin{array}{c}\text { - las reservas } \\
\text { obligatorias y } \\
\text { voluntarias, }\end{array}$ & NO & NO & $\begin{array}{l}\text { D309/12, artículos } 56 \text { al } \\
59 . \\
\text { — Dispone la creación } \\
\text { de reservas, establece } \\
\text { prioridades de pago, } \\
\text { impone límites y re- } \\
\text { glas para la distribu- } \\
\text { ción de utilidades, } \\
\text { orienta posibles desti- } \\
\text { nos de los fondos. } \\
\text { - Dentro de estos már- } \\
\text { genes, se faculta a } \\
\text { la Asamblea General } \\
\text { para decidir. }\end{array}$ & NO \\
\hline - los seguros, & NO & NO & NO & NO \\
\hline
\end{tabular}




\begin{tabular}{|c|c|c|c|c|}
\hline $\begin{array}{l}\text { Contenidos necesarios o } \\
\text { reglamentarios } \\
\text { (D309/12, artículo 21) }\end{array}$ & $\begin{array}{c}\text { Requeridos } \\
\text { de evaluaciones } \\
\text { y negociaciones } \\
\text { previas } \\
\text { (D309/12, artículo 9) }\end{array}$ & $\begin{array}{c}\text { Requeridos } \\
\text { de aprobación } \\
\text { administrativa previa } \\
\text { (D309/12, } \\
\text { artículo 11) }\end{array}$ & $\begin{array}{l}\text { Carácter de otras } \\
\text { regulaciones que les atañan } \\
\text { (DL305/12 y D309/12) }\end{array}$ & $\begin{array}{c}\text { Circunstancias de } \\
\text { obligatoria inscripción } \\
\text { en el Registro Mercantil } \\
\text { (Ind.Metod.MINJUS/13) }\end{array}$ \\
\hline $\begin{array}{l}\text { - las reglas in- } \\
\text { ternas de co- } \\
\text { bros y pagos } \\
\text { y de contrata- } \\
\text { ción; }\end{array}$ & $\begin{array}{l}\text { e) Bienes o servi- } \\
\text { cios que cons- } \\
\text { tituyen el pe- } \\
\text { dido estatal. } \\
\text { g) Los proyectos } \\
\text { de contratos } \\
\text { de arrenda- } \\
\text { miento, usu- } \\
\text { fructo, com- } \\
\text { praventa y } \\
\text { otros. } \\
\text { i) Los insumos } \\
\text { principales a } \\
\text { suministrar. }\end{array}$ & $\begin{array}{l}\text { g) Bienes o servicios } \\
\text { que constituyen } \\
\text { el pedido estatal, } \\
\text { cuando corres- } \\
\text { ponda. } \\
\text { i) Insumos principa- } \\
\text { les a suministrar, } \\
\text { cuando corres- } \\
\text { ponda. }\end{array}$ & $\begin{array}{l}\text { D309/12, artículo } 66 . \\
\text { — Preceptúa el compro- } \\
\text { miso productivo de la } \\
\text { CNA con el Estado; } \\
\text { cumplido este puede } \\
\text { comerciar con sus } \\
\text { producciones en con- } \\
\text { diciones de igualdad y } \\
\text { libertad. }\end{array}$ & NO \\
\hline $\begin{array}{l}\text { - así como las } \\
\text { normas de } \\
\text { contabilidad, } \\
\text { de precios y } \\
\text { tarifas, que } \\
\text { aplicará. }\end{array}$ & $\begin{array}{l}\text { f) Los precios de } \\
\text { bienes y ser- } \\
\text { vicios que se } \\
\text { mantendrán } \\
\text { centralmente } \\
\text { establecidos. }\end{array}$ & $\begin{array}{l}\text { h) Los precios de } \\
\text { bienes y servicios } \\
\text { que se manten- } \\
\text { drán centralmente } \\
\text { establecidos, } \\
\text { cuando corres- } \\
\text { ponda. }\end{array}$ & $\begin{array}{l}\text { D309/12, artículos } 52 \text { y } \\
53 . \\
\text { — Preceptúa la aplica- } \\
\text { ción, por el órgano de } \\
\text { Administración de la } \\
\text { CNA, de las «Normas } \\
\text { Cubanas de Informa- } \\
\text { ción Financiera». }\end{array}$ & NO \\
\hline $\begin{array}{l}\text { I) El régimen ban- } \\
\text { cario, incluidas las } \\
\text { personas facul- } \\
\text { tadas para abrir } \\
\text { y operar cuentas } \\
\text { bancarias, el tipo } \\
\text { de cuentas que } \\
\text { pueden abrir, el } \\
\text { modo de ope- } \\
\text { rarlas, y el modo } \\
\text { de designar a las } \\
\text { personas que po- } \\
\text { drán abrir, ce- } \\
\text { rrar y operar esas } \\
\text { cuentas; }\end{array}$ & NO & $\begin{array}{l}\text { a) ...el tipo de mo- } \\
\text { neda en que ope- } \\
\text { rará. }\end{array}$ & & $\begin{array}{l}\text { 9. El régimen ban- } \\
\text { cario, incluidas } \\
\text { las personas fa- } \\
\text { cultadas para } \\
\text { abrir y operar } \\
\text { cuentas ban- } \\
\text { carias y el tipo } \\
\text { de cuentas que } \\
\text { pueden abrir. }\end{array}$ \\
\hline
\end{tabular}




\begin{tabular}{|c|c|c|c|c|}
\hline $\begin{array}{l}\text { Contenidos necesarios o } \\
\text { reglamentarios } \\
\text { (D309/12, artículo 21) }\end{array}$ & $\begin{array}{c}\text { Requeridos } \\
\text { de evaluaciones } \\
\text { y negociaciones } \\
\text { previas } \\
\text { (D309/12, artículo 9) }\end{array}$ & $\begin{array}{c}\text { Requeridos } \\
\text { de aprobación } \\
\text { administrativa previa } \\
\text { (D309/12, } \\
\text { artículo 11) }\end{array}$ & $\begin{array}{l}\text { Carácter de otras } \\
\text { regulaciones que les atañan } \\
\text { (DL305/12 y D309/12) }\end{array}$ & $\begin{array}{c}\text { Circunstancias de } \\
\text { obligatoria inscripción } \\
\text { en el Registro Mercantil } \\
\text { (Ind.Metod.MINJUS/13) }\end{array}$ \\
\hline $\begin{array}{l}\text { m) El sistema de re- } \\
\text { tribución a los so- } \\
\text { cios, basado en la } \\
\text { cantidad, comple- } \\
\text { jidad y calidad del } \\
\text { trabajo. }\end{array}$ & NO & NO & $\begin{array}{l}\text { D309/12, artículos } 60 \text { al } \\
62 . \\
\text { — Establece como prin- } \\
\text { cipio realizarlo con } \\
\text { arreglo a la «cantidad, } \\
\text { complejidad y calidad } \\
\text { del trabajo». } \\
\text { - Corresponde a la CNA } \\
\text { su forma de cálculo y } \\
\text { de distribución. }\end{array}$ & NO \\
\hline $\begin{array}{l}\text { n) El régimen de } \\
\text { los trabajadores } \\
\text { eventuales. }\end{array}$ & NO & NO & $\begin{array}{l}\text { DL305/12, artículo 26, y } \\
\text { D309/12, artículos } 63 \text { al } \\
65 \text {. } \\
\text { — El salario se pactará } \\
\text { entre el órgano de } \\
\text { administración de la } \\
\text { CNA y el trabajador, } \\
\text { a partir del salario mí- } \\
\text { nimo establecido en el } \\
\text { país. }\end{array}$ & NO \\
\hline $\begin{array}{l}\text { o) La forma en que } \\
\text { efectuará su con- } \\
\text { trol interno. }\end{array}$ & NO & NO & $\begin{array}{l}\text { D309/12, artículos } 45 \text { y } \\
54 \text { al 55. } \\
\text { — Encarga de esta labor } \\
\text { a la Comisión de Con- } \\
\text { trol y Fiscalización. } \\
\text { - Preceptúa la elabora- } \\
\text { ción de un Plan anual } \\
\text { interno, que se ela- } \\
\text { bora tomando en } \\
\text { consideración el pe- } \\
\text { dido estatal y otros } \\
\text { compromisos, y que } \\
\text { será aprobado por la } \\
\text { Asamblea General. }\end{array}$ & NO \\
\hline
\end{tabular}




\begin{tabular}{|c|c|c|c|c|}
\hline $\begin{array}{l}\text { Contenidos necesarios o } \\
\text { reglamentarios } \\
\text { (D309/12, artículo 21) }\end{array}$ & $\begin{array}{c}\text { Requeridos } \\
\text { de evaluaciones } \\
\text { y negociaciones } \\
\text { previas } \\
\text { (D309/12, artículo 9) }\end{array}$ & $\begin{array}{c}\text { Requeridos } \\
\text { de aprobación } \\
\text { administrativa previa } \\
\text { (D309/12, } \\
\text { artículo 11) }\end{array}$ & $\begin{array}{l}\text { Carácter de otras } \\
\text { regulaciones que les atañan } \\
\text { (DL305/12 y D309/12) }\end{array}$ & $\begin{array}{l}\text { Circunstancias de } \\
\text { obligatoria inscripción } \\
\text { en el Registro Mercantil } \\
\text { (Ind.Metod.MINJUS/13) }\end{array}$ \\
\hline $\begin{array}{l}\text { p) El régimen disci- } \\
\text { plinario, causales } \\
\text { y procedimiento } \\
\text { para la sanción. }\end{array}$ & NO & NO & $\begin{array}{l}\text { D309/12, artículos } 67 \text { al } \\
69 . \\
\text { — Preceptúa causales ge- } \\
\text { nerales (5 incisos) que } \\
\text { constituyen infraccio- } \\
\text { nes de la disciplina de } \\
\text { los socios, sin perjuicio } \\
\text { de otras que puedan } \\
\text { prever los Estatutos. } \\
\text { - Reserva a los Estatutos } \\
\text { la regulación del pro- } \\
\text { cedimiento para aplicar } \\
\text { medidas disciplinarias } \\
\text { a los socios, aunque } \\
\text { orienta en este sentido. } \\
\text { - Preceptúa las pautas } \\
\text { para la aplicación de } \\
\text { medidas disciplinarias } \\
\text { a los trabajadores y } \\
\text { remite a la legislación } \\
\text { laboral. }\end{array}$ & NO \\
\hline $\begin{array}{l}\text { q) El régimen de so- } \\
\text { lución de conflic- } \\
\text { tos. }\end{array}$ & NO & NO & $\begin{array}{l}\text { DL305/12, artículos } 27 \\
\text { al } 29 \text {, y D309/12, artícu- } \\
\text { los } 70 \text { al } 74 \text {. } \\
\text { - Predominio de normas } \\
\text { preceptivas, estable- } \\
\text { ciendo un proceso in- } \\
\text { terno detallado, que } \\
\text { puede desembocar en } \\
\text { la vía judicial en caso } \\
\text { de desacuerdo. }\end{array}$ & NO \\
\hline $\begin{array}{l}\text { r) El procedimiento } \\
\text { para modificar los } \\
\text { estatutos. }\end{array}$ & NO & NO & $\begin{array}{l}\text { D309/12, artículo } 22 . \\
\text { — Preceptivo respecto } \\
\text { al órgano facultado } \\
\text { (Asamblea General), } \\
\text { quórum mínimo asis- } \\
\text { tente y quórum a fa- } \\
\text { vor, salvo en la CNA } \\
\text { de hasta veinte socios, } \\
\text { en cuyos estatutos po- } \\
\text { drán establecer otras } \\
\text { reglas. }\end{array}$ & NO \\
\hline
\end{tabular}




\begin{tabular}{|c|c|c|c|c|}
\hline $\begin{array}{l}\text { Contenidos necesarios o } \\
\text { reglamentarios } \\
\text { (D309/12, artículo 21) }\end{array}$ & $\begin{array}{c}\text { Requeridos } \\
\text { de evaluaciones } \\
\text { y negociaciones } \\
\text { previas } \\
\text { (D309/12, artículo 9) }\end{array}$ & $\begin{array}{c}\text { Requeridos } \\
\text { de aprobación } \\
\text { administrativa previa } \\
\text { (D309/12, } \\
\text { artículo 11) }\end{array}$ & $\begin{array}{l}\text { Carácter de otras } \\
\text { regulaciones que les atañan } \\
\text { (DL305/12 y D309/12) }\end{array}$ & $\begin{array}{c}\text { Circunstancias de } \\
\text { obligatoria inscripción } \\
\text { en el Registro Mercantil } \\
\text { (Ind.Metod.MINJUS/13) }\end{array}$ \\
\hline $\begin{array}{l}\text { s) El procedimiento } \\
\text { para la disolución } \\
\text { y la liquidación. }\end{array}$ & NO & NO & $\begin{array}{l}\text { DL 305/12, artículos 15, } \\
30 \text { al 32, y D309/12, ar- } \\
\text { tículos } 75 \text { al } 77 . \\
\text { - Preceptúa que la au- } \\
\text { toridad pública que } \\
\text { autorizó su constitu- } \\
\text { ción, decide sobre su } \\
\text { disolución y liquida- } \\
\text { ción. } \\
\text { - Preceptúa también } \\
\text { que las CNA no po- } \\
\text { drán fusionarse, ex- } \\
\text { tinguirse, escindirse, } \\
\text { ni modificarse sin la } \\
\text { aprobación de esta } \\
\text { autoridad. } \\
\text { - La CNA dispone de los } \\
\text { bienes y derechos re- } \\
\text { sultantes de la liquida- } \\
\text { ción, después de cu- } \\
\text { biertas las deudas. }\end{array}$ & NO \\
\hline- & $\begin{array}{l}\text { I) El proyecto } \\
\text { de estatutos; } \\
\text { y }\end{array}$ & - & NO & NO \\
\hline NO & $\begin{array}{l}\text { m) Otros aspec- } \\
\text { tos que se } \\
\text { consideren } \\
\text { de interés. }\end{array}$ & NO & NO & NO \\
\hline
\end{tabular}




\section{Derechos de autor}

El Boletín de la Asociación Internacional de Derecho Cooperativo es una revista de acceso abierto lo que significa que es de libre acceso en su integridad inmediatamente después de la publicación de cada número. Se permite su lectura, la búsqueda, descarga, distribución y reutilización legal en cualquier tipo de soporte sólo para fines no comerciales y según lo previsto por la ley; sin la previa autorización de la Editorial (Universidad de Deusto) o el autor, siempre que la obra original sea debidamente citada (número, año, páginas y DOI si procede) y cualquier cambio en el original esté claramente indicado.

\section{Copyright}

The International Association of Cooperative Law Journal is an Open Access journal which means that it is free for full and immediate access, reading, search, download, distribution, and lawful reuse in any medium only for non-commercial purposes, without prior permission from the Publisher or the author; provided the original work is properly cited and any changes to the original are clearly indicated. 